\title{
Decolorization and Biodegradation of Direct Blue 2B by Mix Consortia of Bacillus
}

\author{
${ }^{1}$ G. L. Bhoosreddy \\ ${ }^{1}$ Department of Microbiology, Sevadal Mahila Mahavidyalaya, Nagpur. (M.S).India.
}

\begin{abstract}
Mix consortia of Bacillus sp was used to decolorize Direct Blue dye 2B. The bacterial cultures exhibited $60 \%$ decolorization ability within $48 \mathrm{~h}$ at temperature $40^{\circ} \mathrm{C}$ and $\mathrm{pH}$ 7. Maximum rate of decolorization was observed (60\%) when starch was supplemented in the medium. Decolorization of Direct Blue dye $2 B$ was monitored by TLC, which indicated that dye decolorization was due to its degradation into unidentified intermediates. Maximum, dye-decolorizing efficiency was observed at $200 \mathrm{mg} / \mathrm{l}$ concentration of Direct dye 2B. A plate assay was performed for the detection of decolorizing ability of bacteria. Clearing zone (decolorization) was formed surrounding the bacterial culture. Decolorization was confirmed by UV-VIS spectrophotometer. The initial dye solution showed high peak at the wavelength of 540nm. Plate screening method has shown dark brown zone observed around colonies producing ligninolytic enzyme responsible for dye degradation. The pot culture experiment revealed that the Direct Blue $2 B$ dye show phytotoxicity against Allium sativum, but, after degradation of dye, the degraded products obtained show less toxicity.
\end{abstract}

Key words: Biodegradation, Direct blue dye 2B, YE medium, Bacillus

\section{Introduction}

Azo dyes account for the majority of all textile dyestuffs produced and are the most commonly used synthetic dyes in the textile, food, paper making, color paper printing, leather and cosmetic industries (Chang et al., 2001) ${ }^{1}$. Sulfonated azo dyes, the largest class of dyes, have great structural differences and consequently offer a great variety of colors. The discharge of these sulfonated azo dyes has not only a negative aesthetic effect but also some azo dyes and their degradation products, sulfonated and unsulfonated aromatic amines are toxic or even carcinogenic (Myslak and Bolt, 1998) ${ }^{2}$. Much of these studies have emphasized only the decolorization/degradation of dye wastewater, not discussing much about the products released by the cleavage of azo group.

The release of azo dye in to environment is of great concern due to its color, toxicity, mutagenicity and carcinogenicity of the dye, considerable research has been done in evaluating the capability of microorganism in decolorization and degradation of azo dyes especially fungi and bacteria have been reported and reviewed ( Kandelbauer \& Guebitz, 2005) ${ }^{3}$. The present study deals with screening of bacterial strains capable of degrading azo dye, effect of different parameters on dye degradation, phytotoxicity, analysis of degraded products, and determination of factors responsible for dye degradation (enzyme analysis).

\section{Materials and Methods}

Samples were collected in autoclaved bottle from soil, water and sludge from nearby tributary of river containing effluent discharged from the MIDC of Nagpur (Maharashtra) India and kept in cold condition till the sample is brought to laboratory. All chemicals were purchased from Hi-media laboratories, Mumbai (India) and were of analytical grade.

\subsection{Screening of dye degrading organisms}

Isolation of the microbial strains was carried out from the soil, water and sludge samples by enrichment culture technique. $1000 \mathrm{ml}$ yeast extract medium, with $100 \mathrm{mg} / \mathrm{L}$ of Direct blue $2 \mathrm{~B}$ dye, was inoculated with $2 \mathrm{~g}$ of soil, $2 \mathrm{ml}$ of waste water and sludge sample. After $48 \mathrm{hr}$ of incubation, a loopful of sample from the decolorized broth was streaked on yeast extract medium agar plate containing $100 \mathrm{mg} / \mathrm{L}$ of Direct blue 2B dye and colonies showing decolorization zone were selected. Morphologically distinct bacterial strains were selected for screening of dye decolorization. The most efficient strains were then selected for further studies. Isolated bacterial strains were maintained at $4^{\circ} \mathrm{C}$ and frequently subcultured on yeast extract medium slants (Kuo-Cheng Chen et al 2003) ${ }^{4}$.

\subsection{Decolorization studies}

All the decolorization experiments were performed in triplicates. Decolorization study of Direct blue 2B was carried out by addition of $100 \mathrm{mg} /$ lit of dye in $250 \mathrm{ml}$ Erlenmeyer flask containing $100 \mathrm{ml}$ of yeast extract 
medium containing $24 \mathrm{hr}$. old culture of all six bacterial isolates (mix consortia of Bacillus sp). All the studies were carried at $37^{\circ} \mathrm{C}$ and at $\mathrm{pH} 7$. Samples $(2 \mathrm{ml})$ were withdrawn after various time intervals to monitor decolorization rate. Aliquots withdrawn were centrifuged at 7,000 rpm for $7 \mathrm{~min}$, and residual dye concentration in supernatant was measured at $540 \mathrm{~nm}$ for Direct blue 2B. The above mentioned protocol was followed for different studies viz. effect of shaking conditions, effect of different co-substrates and effect of physicochemical parameters and the effect of increasing dye concentrations on decolorization. The percentage decolorization was calculated as follows:

$$
\% \text { Decolorization }=\frac{\text { Initial absorbance }- \text { Observed absorbance }}{\text { Initial absorbance }} \times 100
$$

\subsection{Effect of Temperatures and $\mathrm{pH}$}

Various physicochemical parameters like temperature and $\mathrm{pH}$ were monitored to study their effect on decolorization of Direct blue 2B. Yeast extract medium (100 ml each) with $24 \mathrm{~h}$ old cultures of mix consortia was inoculated with dye $(100 \mathrm{mg} / \mathrm{lit})$ and incubated at, $20^{\circ}, 30^{\circ}, 40^{\circ}, 50^{\circ}$ and $60^{\circ} \mathrm{C}$ and at different $\mathrm{pH}$ as $3,5,7$, 9, and 11 .

\subsection{Effect of Dye Concentration}

Various dye concentrations ranging from 200 to $1000 \mathrm{mg} /$ lit were added to yeast extract medium in order to examine the effect of varying initial dye concentrations on decolorization.

\subsection{Effect of co-substrates}

Additional co-substrates were added individually to yeast extract medium like glucose, starch, sucrose, maltose, and fructose at $0.5 \%$ concentration.

\subsection{Phytotoxicity}

The dye and degraded metabolites of Direct blue 2B obtained were used for toxicity study. The phytotoxicity study was carried out at room temperature on Allium sativum by irrigating separately with $20 \mathrm{ml}$ of dye and degraded product. Control set was carried out using plain water. Percentage of germination was recorded after 10 days. The leachate was extracted after $48 \mathrm{hr}$. for irrigation.

\subsection{Analysis of degraded metabolite}

Thin Layer Chromatography was used for separation of degraded product of azo dye. The solvent system used was ethanol: water: methanol (3:1:3).

\subsection{Determination of factors responsible for dye degradation (Enzyme analysis)}

Decolorization is mainly a biological process, either a direct enzymatically catalyzed reaction involving non-specific enzymes or a reaction with enzymatically reduced electron carriers. To study the possible enzymes involved in decolorization Plate screening method was used. $0.1 \mathrm{ml}$ decolorized broth is poured in sterilized petriplate and then molten yeast extract agar with separately sterile $0.5 \%$ tannic acid is added and agar is allowed to solidify and plate is incubated at $30^{\circ} \mathrm{C}$ for 4 days.

\subsection{Screening of dye degrading organisms}

\section{Results and Discussion}

The main objective of this study was to screen out bacterial strains capable of decolorization and biodegradation of Direct blue 2B azo dye. Present study resulted in isolation of Bacillus strains all capable of degrading azo dye. All Bacillus strains isolated from waste water indicates the natural adaptation of these bacteria to survive in the presence of toxic dye. All six bacterial isolates were able to degrade dye at wide range of temperature $30-40^{\circ} \mathrm{C}$ and decolorization at alkaline $\mathrm{pH}$ and optimum at neutral to alkaline $\mathrm{pH}$. The cosubstrates added to enhance the process of decolorization specially, Starch, Maltose, Fructose carbon source were found to speed up decolorization. The cultures show dye degradation at varying dye concentration from $200 \mathrm{mg}-1000 \mathrm{mg} /$ lit but at higher concentration ability of decolorization and degradation decreased as the toxicity increased. By performing TLC the $R f$ values were different compared to the dye before treatment and after 48 hour of incubation period for decolorization. Ligninolytic enzymes, viz., laccase, tyrosinase and lignin peroxidase, and manganese peroxidase were responsible for dye degradation. Phytotoxicity studies revealed that that degraded dye showed less toxicity as compared to the original dye on seed germination of Allium sativum.

\subsection{Effect of different temperatures on dye degradation}

The dye decolorizing ability by the cultures were found to increase with increase in incubation temperature with maximum activity attained at $40^{\circ} \mathrm{C}$ further increase in incubation temperature to $50^{\circ} \mathrm{C}$ resulted in many fold reduction in decolorization activity of the cultures. Maximum dye decolorization activity was 
attained with the mix consortia at $40^{\circ} \mathrm{C}$ (Fig. $3.2 \&$ photo plate3. 2). Wong and Yuen (1996) ${ }^{5}$ reported that Klebsiella pneumoniae RS-13 exhibited methyl red decolorization at temperatures varying from $23^{\circ} \mathrm{C}$ to $37^{\circ} \mathrm{C}$ whereas at $45^{\circ} \mathrm{C}$ decolorization was completely inhibited. Decline in decolorization activity at higher temperature can be attributed to the loss of cell viability or to the denaturation of the azoreductase enzyme (Pearce, C. I., Lloyd, J. R. and Guthrie, J.T., 2003) ${ }^{6}$.

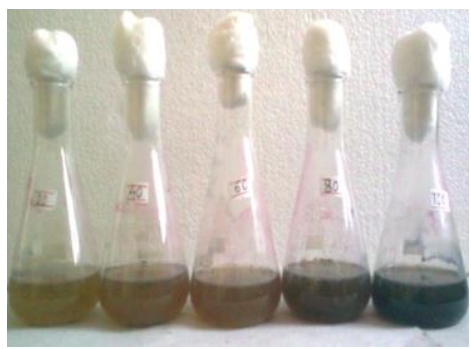

\section{Photo plate: 3.2 Effect of different temperatures on Percent degradation Direct blue 2B dye} decolorization

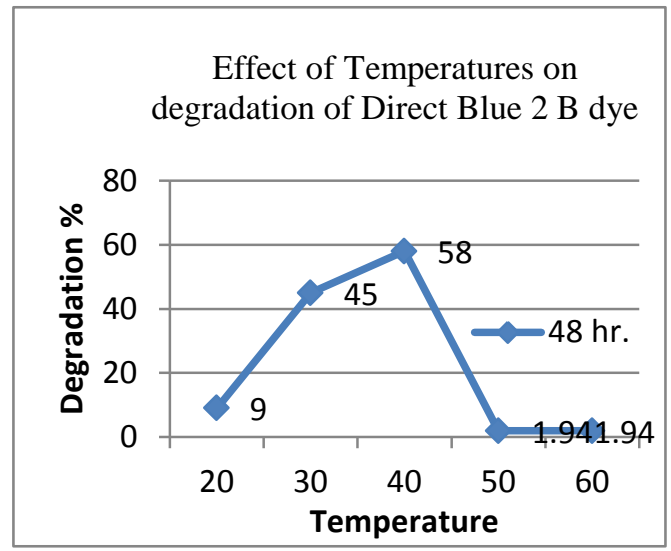

Figure: 3.2 Effect of different temperatures on Percent degradation of Direct Blue 2B dye

\subsection{Effect of different $\mathrm{pH}$ on dye degradation}

It was found that change in $\mathrm{pH}$ significantly affect the decolorization rate .The mix consortia exhibited decolorization activity at $\mathrm{pH} 3-11$. The isolated Bacillus culture generally exhibited maximum decolorization at $\mathrm{pH}$ values 7-9 with marked reduction in decolorizing activity above $\mathrm{pH} 9$ (Fig 3.3 \& photo plate3. 3). It has been reported $E$. coli and $P$. luteola, both exhibit best decolorization rate at $\mathrm{pH} 7$ with constant decolorization

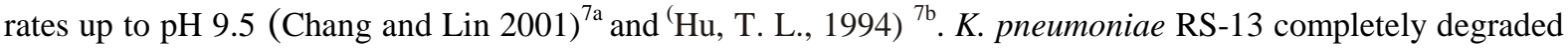
methyl red in $\mathrm{pH}$ range from 6.0 to 8.0 (Wong and Yuen 1996). It has been reported that generally azo dye reduction by bacterial cultures to more basic aromatic amines leads to rise in $\mathrm{pH}$ of medium by about $0.8-1.0$ (Knapp and Newby 1995, Hu 1994) ${ }^{8}$.

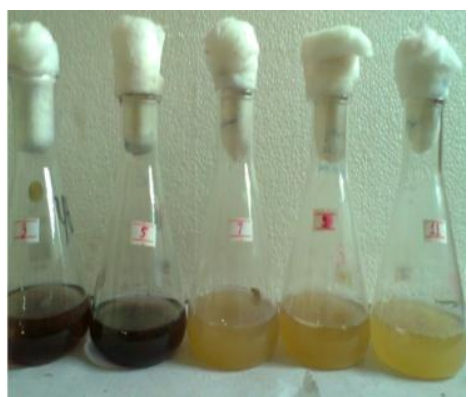

Photo plate: 3.3. Effect of different pH on Direct blue 2B dye Decolorization 
Effect of $\mathrm{pH}$ on degradtion of Direct Blue 2B

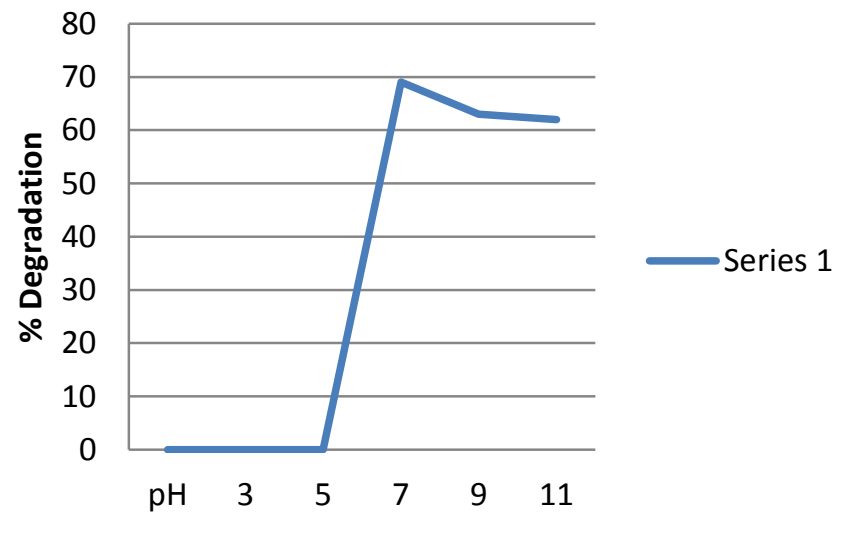

Figure: 3.3. Effect of different $\mathrm{pH}$ on percent degradation of Direct blue 2B dye

\subsection{Effect of different dye concentration}

The mix consortia have shown decolorization activity at concentration between $200-1000 \mathrm{mg} / \mathrm{l}$. The decolorization activity of the cultures was strongly inhibited at higher concentration of dye, (Fig 3.4 \& photo plate 3.4. It has been proposed that dye concentration can influence the efficiency of microbial decolorization through combination of factor including the toxicity imposed by dye at higher concentration (Pearce et al 2003). Thus mix consortia of Bacillus sp isolated, could decolorize dye much above the reported dye concentration in wastewaters, and can be successfully employed for treatment of dye bearing industrial wastewaters.

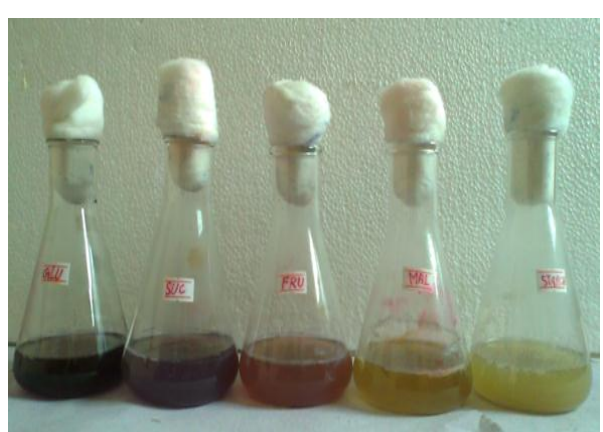

\section{Photo plate: 3.4. Effect of different dye Concentration of Direct Blue 2 on Degradation}

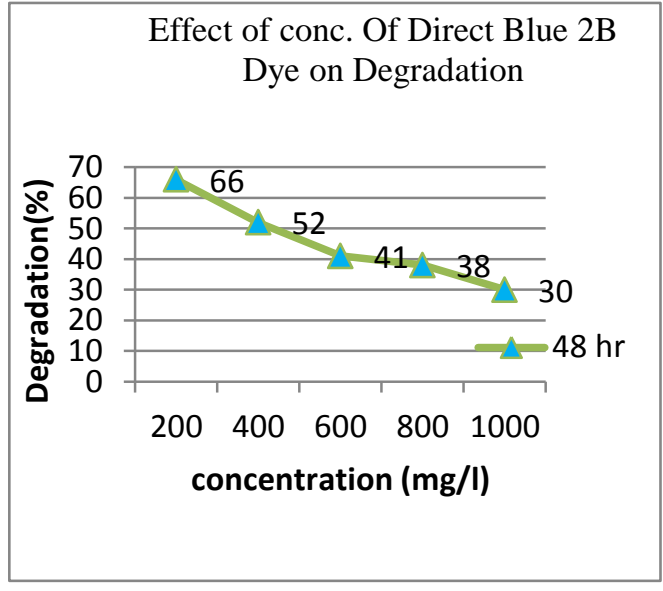

Figure: 3.4. Effect of different dye Concentration on percent degradation of Direct Blue 2B dye

\subsection{Effect of co-substrates in medium}

Different carbon source were supplemented viz. glucose, fructose, sucrose, starch, maltose at $0.5 \%$ concentration with yeast extract. The culture exhibited efficient decolorization in presence of starch, maltose, fructose . The maltose, and starch served as good co-substrates (Fig $3.5 \&$ photo plate3. 5). Starch as best cosubstrate can be explained on the basis that, there was a significant shortening of lag phase of $P$. ostreatus growth that caused a decrease in incubation time from 4 to 3 days to cause maximum dye removal, Maltose also showed stimulatory effect on dye decolorization ( Kashif Jilani, Muhammad Asgher, Haq N. Bhatti and Zahid Mushtaq 2010) ${ }^{9}$. 


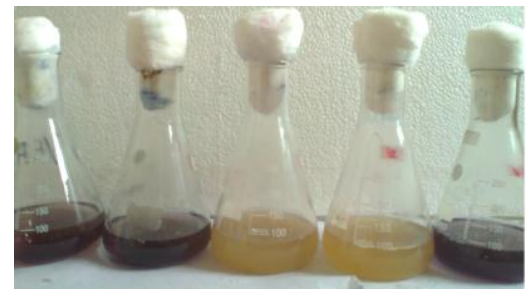

\section{Photo plate: 3. 5. Effect of Co-substrates on Degradation of Direct blue 2B Dye}

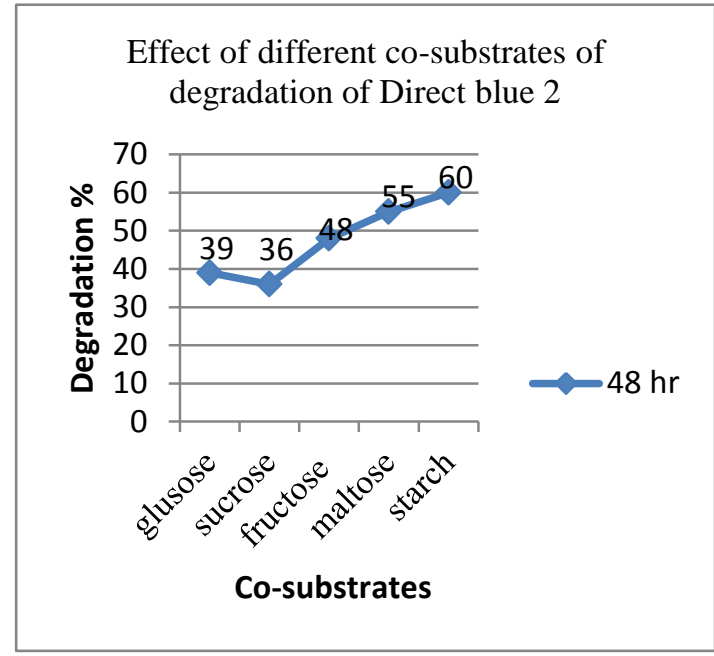

Figure: 3.5 Effect of Co-substrates on Degradation of Direct blue 2B Dye

\subsection{Phytotoxicity}

Most common methods employed to study phytotoxicity are monitoring of seed germination and plant growth. As dye waste from industries are most commonly discharged to the nearby agricultural area and water bodies, it was important to reveal the toxicity. The phytotoxicity study carried out at room temperature on Allium sativum show considerable decrease in growth in presence of higher concentration of dye (Table 3.6). Similar results were observed by (Jadhav et al 2009) ${ }^{10}$ on \% germination of both Triticum aestivum and Phaseolus mungo seeds with Direct Orange 39 as compared with its degraded metabolites. The phytotoxicity study showed that length of plumule and radical was affected in case of the dye Direct Orange 39 whereas with degraded metabolites it showed significant growth, compared to control which indicate that, the isolated Pseudomonas aeruginosa strain $\mathrm{BCH}$ was not only able to decolorize Direct Orange 39 but was also able to detoxify it.

Table: 3.6. Effect of Direct blue 2B dye and degraded metabolite on percent germination of Allium sativum

\begin{tabular}{|l|c|c|c|}
\hline Seeds of Allium sativum & Water & Degraded Product (mg) & Dye concentration ( mg) \\
\hline$\%$ Germination & 10 & 9 & 3 \\
\hline
\end{tabular}

\subsection{Determination of factors responsible for dye degradation (Enzyme analysis)}

Plate screening method show dark brown zone was observed around colonies producing ligninolytic enzyme responsible for dye degradation (photo plate 3.7). Extracellular oxidoreductases, including lignin peroxidase $(\mathrm{LiP})$, manganese peroxidase $(\mathrm{MnP})$ and laccase produced by wood-decomposing microorganism, are directly involved in the degradation of lignin in their natural lignocellulosic substrates and various xenobiotic compounds including dyes (Abrahão et al., 2008) ${ }^{11 .}$ The production of ligninolytic enzymes is observed as a colourless halo around microbial growth (Dhouib et al., 2005) ${ }^{12}$. So, the lignin degradation capability of microbes is initially screened indirectly on solid media containing different indicator compounds. 


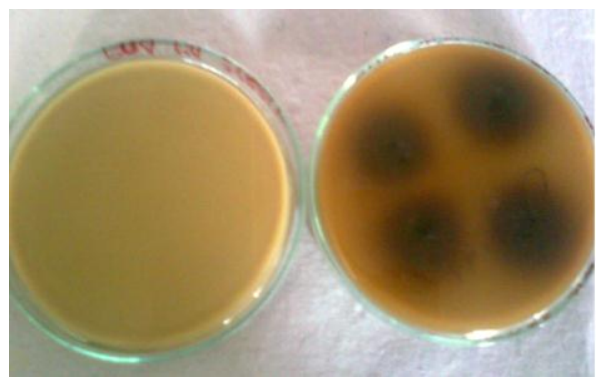

\section{Photo plate: 3.7. Plate screening assay for ligninolytic activity}

\subsection{Analysis of degraded metabolite}

TLC: The degraded metabolite of Direct blue 2 were analyzed by TLC. TLC pattern of standard and treated sample of both dye were different spot with $R f$ Value of standard Direct blue 2 dye : 0.88 were not present in treated sample pattern and $R f$ value of treated Direct blue 2B dye : 0.92 (photo plate 3.7)

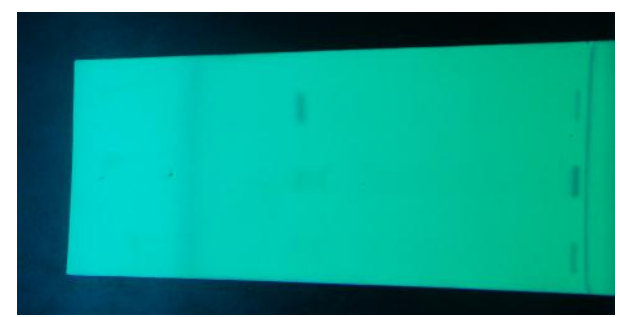

\section{Photo plate: 3.8. TLC analysis of the degraded Direct dye 2B}

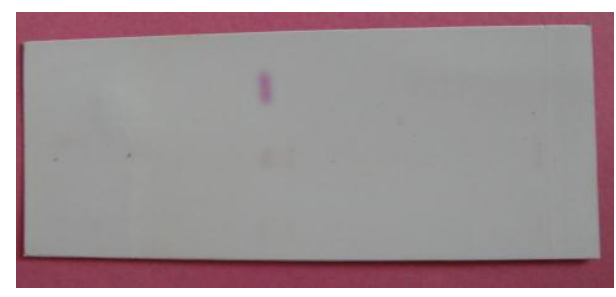

\section{Conclusion}

From the present study, it was concluded that consortia of Bacillus sp show that best temperature and $\mathrm{pH}$ for Direct Blue 2B azo dye is $40^{\circ} \mathrm{C}$ and 9 , respectively. The most efficient co-substrate was Starch, Maltose, and Fructose. The Direct Blue dye 2B showed phytotoxicity against Allium sativum, after efficient degradation of dye, the degraded products obtained show less toxicity. Direct blue dye 2B degradation was confirmed by TLC by differences in $R f$ values and ligninolytic enzyme responsible for degradation.

As a conclusion, this study reports that the potential of Bacillus consortia can be used for decolorization and degradation of azo dyes in contaminated industrial effluents and the degraded dyes in the effluent can be safely discharged into water streams without any effect on natural flora.

\section{References}

[1]. Chang, J.S and Lin, C.Y. Decolorization kinetics of a recombinant Escherichia coli strain harboring azo-dye-decolorizing determinants from Rhodococcus sp. Biotechnol. Lett, 23, (2001): 631-636.

[2]. Myslak, Z. W. and H. M. Bolt. Occupational Exposure to Azo Dyes and Risk of Bladder Cancer, Zbl. Arbeitsmed, (1998): 38, 310.

[3]. Kandelbauer and Guebitz. Bioremediation for the decolorization of textile dyes, a review. ... J of Bacteriology, 183, (2005), 54265430 .

[4]. Kuo-Cheng Chen, Jane-Yii Wua, Dar-Jen Liou, Sz-Chwun John Hwang. Decolorization of the textile dyes by newly isolated bacterial strains. J of Biotechnology, 101 (2003), 57- 68.

[5]. Wong P.K and P.Y. Yuen. Decolorization and biodegradation of N,Ni-dimethyl-p-phenylenediamine by Klebsiella pneumoniae RS13 and Acetobacter liquefaciens S-1. J of Applied Microbiology, 85, (1998): 79-87.

[6]. Pearce, C. I., Lloyd, J. R. and Guthrie, J.T. The removal of color from textile wastewater using whole bacterial cells: a review. Dyes and pigments 58, (2003), 179-186.

[7a]. Chang J.S, Chou C, Lin YC, Lin PJ, Ho JY, Hu TL. Kinetic characteristics of bacterial azo dye decolorization by Pseudomonas luteola. Water Res 35:2841-285dye using a Pseudomonas luteola strain. Biotechnology Progress, 16, (2001): 979-985.

[7b]. Hu, T. L. Decolorization of reactive azo dyes by transformation with Pseudomonas luteola. Bioresources technology 49: (1994): 4751.

[8]. Knapp, J. S \& Newby P. S. The microbial decolorization of an industrial effluent containing a diazo linked chromophore. Water research 29, (1995), 1807-1809. 
[9]. Kashif Jilani, Muhammad Asgher, Haq Nawaz Bhatti and Zahid Mushtaq. Shake Flask Decolourization Of Direct Dye Solar Golden Yellow R by Pleurotus Ostreatus. Journal of Chemical Society Pakistan 01, 33,(2010). PP, 209-214.

[10]. Jyoti P. Jadhav, Swapnil S. Phugare Rhishikesh S. Dhanve, Shekhar B. Jadhav. A Rapid Biodegradation and Decolorization Of Direct Orange 39 (Orange II) by isolated Pseudomonas aeruginosa Strain BCH, Springer Science. Biodegradation 21, (2009): 453463.

[11]. Abrahão MC, Gugliotta AM, Silva RD, Fujieda RJY, Boscolo M, Gomes E. Ligninolytic activity from newly isolated basidiomycete strain and effect of their enzymes on the azo dye orange II decolourisation. Ann. Microbiol. 58, (2008): 427-432.

[12]. Dhouib A. Hamza M, Zouari H, Mechichi T, Hamidi R. Labat M, Martinez MJ, Sayadi S. Screening for ligninolytic enzyme production by diverse fungi from Tunisia, World. J. Microbial. Biotechnology 21, (2005): 1415-1423 